\title{
Sexual differences in hair morphology of coyote and white-tailed deer: males have thicker hair
}

\author{
Andrew K. Davis ${ }^{1,3, \star}$, Stacey P. Brummer ${ }^{2}$ \& John Shivik ${ }^{2}$
}

1) D.B. Warnell School of Forestry and Natural Resources, The University of Georgia, Athens, GA, USA 30602

2) USDA Wildlife Services National Wildlife Research Center Utah State University, Room 163 BNR Building, Logan, UT, USA 84322

3) current address: Odum School of Ecology, The University of Georgia, Athens, GA, USA 30602 ('corresponding author's e-mail: akdavis@uga.edu)

Received 20 Jan. 2010, revised version received 25 Aug. 2010, accepted 26 Aug. 2010

Davis, A. K., Brummer, S. P. \& Shivik, J. 2010: Sexual differences in hair morphology of coyote and white-tailed deer: males have thicker hair. - Ann. Zool. Fennici 47: 411-416.

The fur of mammals serves many functions, including thermoregulation, camouflage or visual signaling to conspecifics. Fine-scale features of fur, such as hair morphology are often examined by researchers, especially in animals where pelage is of economic importance. Certain studies from this literature body show that males of many species appear to have thicker guard hair than females. Here, we examined this possibility in coyote (Canis latrans) and white tailed deer (Odocoileus virginianus) from captive populations in Utah and Georgia, USA. We used image analysis procedures to examine 402 guard hairs from 24 captive coyotes and 568 guard hairs from 29 captive deer, measuring the length and diameter of each hair. In both species, males had significantly thicker hairs than females; in coyotes, male hairs were 17\% thicker, in deer, male hairs were $15 \%$ thicker. These differences are comparable to other species, where male hair is between $7 \%-20 \%$ thicker than those of females (in all species the average difference is $13 \%$ ). Considering that there are hundreds of thousands of hairs on any given animal, this difference per unit hair could translate into considerable differences in overall pelt characteristics between sexes. The reason for this difference could relate to the sensitivity of mammalian hair to androgens, such as testosterone, which are more abundant in males of all species. Experimental studies and population surveys demonstrate that high levels of androgens stimulate body hair to grow thicker in diameter. Thus, the greater levels of testosterone in males would act to promote thicker hair. By this same mechanism, within any given collection of males, those with greater levels of androgens should also display greater hair thickness. While further research would be needed to verify this, results from this study nevertheless emphasize the knowledge gaps that yet remain in our understanding of the basic nature of mammalian fur. 


\section{Introduction}

The properties of mammalian fur have been studied for many decades and on a plethora of species, yet it is surprising that our collective understanding of the full functional significance of mammalian hair is not yet complete. One of the most important functions of mammalian fur is thought to be thermoregulation, since in most species, fur is much thicker and deeper in winter than in summer (Ogle \& Farris 1973, Jacobsen 1980, Kulak \& Wajdzik 2006). Depth of fur is primarily modified by changes in hair length, especially of the coarse guard hair that overlays the finer underfur hair in most mammals. In fact, guard hair length is thought to be one of the primary characteristics influencing the degree of heat conduction in mammals (McClure \& Porter 1983), with hair density being the other (Korhonen \& Harri 1989). Guard hair along the dorsal surface of many species can also be raised ('piloerected'), which is a visual sign of aggression and/or apprehension in Canids (Fox 1969). Furthermore, variations in pigmentation of hair, especially of the outer guard hair, can also serve as visual signals to conspecifics or as camouflage (Caro 2005). Each of these functions is commonly raised by mammalogists when referring to fur properties, although there are several bodies of research (on hair morphology) outside the field of mammalogy that may offer additional insights into mammalian hair function, particularly those studies where sexual differences in hair were examined.

There are many species of wool-bearing mammals that are studied because of the economic importance of their fur. These species include blue foxes (Alopex lagopus) (Blomstedt 1998), cashmere goats (Capra spp.) (Celi et al. 2005), domestic sheep (Ovis aries) (Adams \& Cronje 2003) and even wild muskoxen (Ovibos moschatus) (Rowell et al. 2001). There is another body of literature on hair properties of primates (Inagaki 1986), including humans (Sağsöz et al. 2004), some of which was actually conducted decades ago (Wynkoop 1929, Atkinson et al. 1959), but is nevertheless important. And finally, there is a large amount of research to draw upon from the biomedical or dermatol- ogy literature, much of which is conducted on humans or human models (e.g. Lucky et al. 1986). Interestingly, throughout this disparate body of literature, there is at least one recurring pattern: that hair shafts of male animals tend to be thicker (i.e. they have a greater diameter) than females. This has been shown in a wide assortment of animals, such as muskoxen (Rowell et al. 2001), goats (Koul et al. 1987) and monkeys (Inagaki 1986). The significance of this pattern is unknown, and it has also largely gone unnoticed, perhaps because of the scattered nature of the literature on hair morphology. However, the pattern may indicate some sex-related difference in fur function. In any case, it is an issue that warrants additional study, first by investigating the idea in additional, non-domesticated, mammalian species. In this study, we report the results of such an investigation into sexual differences in guard hair morphology from two very distinct species of mammals from North America, the coyote (Canis latrans) and white tailed deer (Odocoileus virginianus).

\section{Material and methods}

\section{Subjects}

The coyotes examined in this study were part of a captive population housed at the National Wildlife Research Center, Predator Research Facility in Millville, UT, USA. The population consists of 98 individuals, which are fed daily rations of $650 \mathrm{~g}$ of commercially available mink food (Fur Breeders Agricultural Cooperative, Logan, UT). The enclosure environment consists of a short grass and alfalfa mixture with small patches of bare ground. The deer in this study were members of a captive population maintained at the Whitehall Deer Research Facility, of the Daniel B. Warnell School of Forestry and Natural Resources, University of Georgia, Athens, GA, USA. This facility housed about 80 deer in 5 large outdoor paddocks (0.4-0.8 ha). All deer in this population are fed $21 \%$ protein ration (Meadows Edge, 960 Honey Ridge, Millen, Georgia, USA), with fresh perennial peanut hay and water available ad libitum. 


\section{Hair sampling}

Hairs from both coyotes and deer were obtained when animals were immobilized for unrelated studies or procedures during the summer of 2009. For the coyotes, members of the Logan station staff used a surgical clamp to pluck a small tuft of hair from the back of the anesthetized coyote's neck. Tufts varied in size, but most contained over 50 hairs, which were a mix of guard hair and underfur hair. For the purposes of this study, guard hairs from 10 male and 14 female coyotes, which were between 1 and 10 years of age, were used. These individuals were sampled between May and September 2009. The deer hair was obtained in a similar manner from immobilized animals (i.e. a tuft was pulled from the back of the neck). We sampled 7 male and 22 female deer between 23-25 August 2009. The deer varied in age from $2-8$ years. All hair samples were stored in plastic bags until measurement.

\section{Measuring hair}

The hair samples varied in size, and in the number of guard hairs versus underfur hairs. From these samples we attempted to measure 20 intact guard hairs for each individual, although this was not always possible when samples were small, or when the sample included many broken hair shafts. Thus, in a small number of animals, we could only obtain between 8-15 intact guard hairs for measurement. The guard hairs were measured using an image analysis approach that generally followed procedures outlined in Davis (2010). Briefly, the 20 hairs from each individual were laid flat on a transparency sheet and a clear sheet of self-laminating plastic placed over them, creating a sealed, transparent hair 'mount'. Each mount was scanned using a standard flatbed scanner set to $1200 \mathrm{dpi}$. To create color contrast between the hairs and the background, the hair mounts were scanned in front of a green plastic sheet. The resulting hair images were imported into an image analysis program (FoveaPro, www.reindeergraphics.com) for measurement. Here, each hair was digitally selected and its total length (regardless of curvature) was measured in $\mathrm{mm}$, based on prior calibration of the software using a scanned ruler image. Then, a 4-mm section of the shaft of each hair was selected at a point midway along the shaft, and the width of the shaft was measured. All measurements were automatically exported to a text file during the image analysis procedures.

\section{Data analysis}

Hair widths $(\mu \mathrm{m})$ were examined separately for coyotes and deer, but with a similar approach for both. For each species we used a mixed-model ANCOVA design where the hair width was the dependent variable, the individual animal was a random factor, sex was a fixed factor and the hair shaft length was a covariate, to account for the possibility that longer hair may be thicker (Inagaki 1986). For each analysis we also initially included the animal age as a fixed factor, but in both deer and coyote, age was not significant in the initial models ( $p>0.5$ for both) and it was therefore removed from final models. Finally, since the coyotes were sampled throughout a 5-month period, we included month of sampling as a fixed factor in the coyote model. Analyses were conducted using the Statistica 6.1 software package (Statistica 2003).

\section{Results}

Across all 24 coyotes examined in this study (402 hairs), the average length of guard hair was $80.6 \mathrm{~mm}$ and ranged from $45-105 \mathrm{~mm}$ (Table 1). This is compared to a maximum length of $90 \mathrm{~mm}$ reported by Tumlison (1983) for coyotes in Arkansas, a range of 44-112 $\mathrm{mm}$ reported by Hilton and Kutscha (1978) for coyotes in Maine, and 80-115 mm for coyotes in Alberta (Kennedy 1982). Meanwhile, the average guard hair diameter for all coyotes was $70.1 \mu \mathrm{m}$, with males having thicker hairs, on average than females (76.8 $\mu \mathrm{m}$ versus $65.7 \mu \mathrm{m}$, Table 1). Consistent with this difference, the mixed-model ANCOVA showed a significant effect of sex on coyote hair width (Table 2), after taking into account varia- 
Table 1. Summary of dorsal guard hair dimensions from male and female coyotes and white-tailed deer. Hairs from 10 male and 14 female coyotes were measured (402 total hairs), and from 7 male and 22 female deer (568 total hairs).

\begin{tabular}{lrrrr}
\hline Parameter & Mean & SD & Min & Max \\
\hline $\begin{array}{l}\text { Coyote } \\
\text { Hair Length }(\mathrm{mm})\end{array}$ & & & & \\
$\quad$ Females & 81.61 & 10.24 & 49.41 & 98.78 \\
$\quad$ Males & 79.02 & 15.54 & 45.44 & 105.44 \\
$\quad$ Both sexes & 80.59 & 12.65 & 45.44 & 105.44 \\
Hair Diameter $(\mu \mathrm{m})$ & & & & \\
$\quad$ Females & 65.74 & 17.02 & 41.66 & 129.23 \\
$\quad$ Males & 76.78 & 23.49 & 41.66 & 139.52 \\
$\quad$ Both sexes & 70.10 & 20.53 & 41.66 & 139.52 \\
Deer $\quad$ & & & & \\
Hair Length $(\mathrm{mm})$ & & & & \\
$\quad$ Females & 21.17 & 4.78 & 8.20 & 36.00 \\
$\quad$ Males & 21.63 & 4.17 & 13.49 & 31.10 \\
$\quad$ Both sexes & 21.28 & 4.65 & 8.20 & 36.00 \\
Hair Diameter $(\mu \mathrm{m})$ & & & & \\
$\quad$ Females & 80.11 & 17.09 & 41.64 & 130.56 \\
$\quad$ Males & 92.03 & 10.42 & 58.46 & 121.30 \\
$\quad$ Both sexes & 82.83 & 16.58 & 41.64 & 130.56 \\
\hline
\end{tabular}

tion among individuals and month of sampling (both significant). Interestingly, there was no significant effect of hair length on hair width in coyotes (Table 2).

Guard hairs of white-tailed deer were considerably shorter than those of coyotes, being $21.3 \mathrm{~mm}$ in length on average across all 568 hairs (Table 1). This is compared to values of $26-32 \mathrm{~mm}$ in white-tailed deer from southeast Georgia (Brisbin \& Lenarz 1984) and an average of $17.5 \mathrm{~mm}$ in white-tailed deer from the northeastern United States (Jacobsen 1980). Guard hair widths averaged $82.8 \mu \mathrm{m}$ across all
29 deer, and as with coyotes, the average thickness of male deer hairs was larger than that of females (92.0 $\mu \mathrm{m}$ versus $80.1 \mu \mathrm{m}$, Table 1). Moreover, the mixed-model ANCOVA showed that the sexes differed significantly in hair width after effects of individual and hair length were accounted for (Table 2).

For comparison, the average hair thickness of male and female coyotes and deer obtained in this study are shown in Table 3, along with similar values from the published literature on other mammals. This table shows that the magnitude of the sex difference in coyotes (male hairs were on average $17 \%$ thicker than those of females) and deer (male hairs were 15\% thicker than female hairs) appeared to be on par with that of other species, which ranged from 7\%-19.8\%. Furthermore, if the average hair diameters of males and females from all species in this table are compared statistically, we find that male hairs are significantly thicker than those of females (paired $t$-test: $t=3.19, \mathrm{df}=$ $5, p=0.024$ ), with male hairs being on average $13 \%$ thicker than female hairs.

\section{Discussion}

Results from this study demonstrated that male guard hairs of coyote and deer tend to be thicker in diameter than those of females, which is a pattern that has been found in a number of other mammalian species. In fact, the consistency of the pattern in each study where sexes have been considered separately suggests that this may be a universal pattern in mammals. Furthermore, the

Table 2. Summary of mixed-model ANCOVA models examining factors influencing guard hair widths of coyotes and white-tailed deer. Hair length was a covariate and individual animal was a random factor in both analyses.

\begin{tabular}{lrrrrrr}
\hline Explanatory variable & df effect & MS effect & df error & MS error & $F$ & $p$ \\
\hline Coyote & & & & & & \\
$\quad$ Hair Length & 1 & 0.000 & 19.727 & 0.002 & 0.076 & 0.786 \\
$\quad$ Individual Animal & 18 & 0.002 & 377.000 & 0.000 & 7.473 & $<0.001$ \\
$\quad$ Month & 4 & 0.005 & 18.547 & 0.002 & 2.988 & 0.046 \\
$\quad$ Sex & 1 & 0.011 & 17.601 & 0.002 & 5.098 & 0.037 \\
Deer & 1 & 0.005 & 33.890 & 0.001 & 5.732 & 0.022 \\
$\quad$ Hair Length & 27 & 0.002 & 538.000 & 0.000 & 9.448 & $<0.001$ \\
$\quad$ Individual Animal & 1 & 0.014 & 27.022 & 0.002 & 8.336 & 0.008 \\
Sex & & & & & & \\
\hline
\end{tabular}


magnitude of the difference between sexes found here is also similar to that reported in other species (Table 3), which is on average around $13 \%$. If one considers that there are many hundreds of thousands of guard hairs on any given animal (white-tailed deer have between 750-1000 guard hairs per $\mathrm{cm}^{2}$; Moen \& Severinghaus 1984), this seemingly small difference in hair diameter would translate into a considerable difference in overall fur mass and thickness (of coat) between males and females.

The most plausible biological explanation for the pattern we discovered may be the mammalian hair's sensitivity to androgenic hormones (i.e. such as testosterone). These are the hormones that promote the growth of secondary sexual characteristics in males, such as facial and chest hair in humans. In fact, this same mechanism appears to promote greater hair diameter as well; within the biomedical literature, there is work showing that hamsters given exogenous testosterone grow thicker hairs (Lucky et al. 1986). The same is true if humans are given androgen supplements (their body hair grows thicker) (Giltay \& Gooren 2000). Interestingly, the same study showed that if testosterone levels are experimentally decreased, hairs become thinner. Furthermore, population-level surveys of human females have found a positive relationship between individual hair thickness and natural levels of androgens (Sağsöz et al. 2004). Plus, measurements of hairs in different parts of the human body show that hairs tend to be thicker over androgen-dependent sites (Riggott \& Wyatt 1983). Combined, these studies all suggest that males tend to have thicker hair than females because males of all species tend to have greater levels of testosterone and other andro- gens than females (Ferguson 1985).

If androgen-dependence is indeed the reason for the sex-based differences in hair thickness, one may also expect that within a given cohort of males, those individuals with greater levels of testosterone would have thicker guard hairs. Since this pattern has been found in humans (Sağsöz et al. 2004), it would not be unreasonable to expect this in other mammalian species. In fact, this may be an area that could be explored in future investigations, since if it bears true, then it may eventually be possible for researchers to use hair thickness as a simple indirect indicator of individual testosterone level in mammalian research projects.

While the mechanistic explanation for the pattern uncovered here appears logical, the functional significance of thicker male guard hairs is less apparent. We consider it unlikely that this has anything to do with thermoregulation, since hair length, not thickness is one of the primary factors regulating fur depth, and therefore heat transfer/loss (e.g. Jacobsen 1980, Moen \& Severinghaus 1984). Moreover, it would seem unlikely that males would have different thermoregulation requirements than females at all. In support of this, Moen and Severinghaus (1984) found no sex-related differences in hair depth of white-tailed deer. One possibility may be that thicker hair serves as a signal to conspecifics when hairs on the back of the animal are raised, as in Canids (Fox 1969). Or perhaps the thick guard hairs serve a protective function against wounding during physical combat and aggression between males. Whatever the function may be, results from this study highlight how our understanding of the nature of mammalian fur is not yet complete.

Table 3. Average guard hair diameter of male and female mammals reported in the published literature and this study.

\begin{tabular}{|c|c|c|c|c|}
\hline Species & Males $(\mu \mathrm{m})$ & Females $(\mu \mathrm{m})$ & Difference (\%) & Source \\
\hline Goat & 13.3 & 12.1 & 9.9 & (Koul et al. 1987) \\
\hline Muskox & 21.5 & 20.1 & 7.0 & (Rowell et al. 2001) \\
\hline Japanese monkey & 51.8 & 43.3 & 19.6 & (Inagaki 1986) \\
\hline Llama & 43.0 & 39.4 & 9.1 & (Martinez et al. 1997) \\
\hline White-tailed deer & 92.0 & 80.1 & 14.9 & This study \\
\hline Coyote & 76.8 & 65.7 & 16.9 & This study \\
\hline Average difference & & & 12.9 & \\
\hline
\end{tabular}




\section{Acknowledgments}

We thank David Osborn for assistance with collecting deer hair, as well as Mike Cherry, Daniel Stull, Will Gulsby, Vanessa Lane, Graham Marsh, Susan Ellis-Felege, Aaron Hecht and Kevin Keel for their assistance with handling the deer. Erika Cologgi, Patrick Darrow, Mike Davis, Jeff Schultz and Melissa Weber assisted with coyote hair collection and animal care. The manuscript was improved after helpful discussions with Peter Davis and Sonia Altizer, and from comments by two anonymous reviewers. AKD was supported by a grant from the Morris Animal Foundation during this project.

\section{References}

Adams, N. R. \& Cronje, P. B. 2003: A review of the biology linking fibre diameter with fleece weight, liveweight, and reproduction in Merino sheep. - Australian Journal of Agricultural Research 54: 1-10.

Atkinson, S. C., Cormia, F. E. \& Unrau, S. A. 1959: The diameter and growth phase of hair in relation to age. British Journal of Dermatology 71: 309-311.

Blomstedt, L. 1998: Pelage cycle in blue fox (Alopex lagopus): a comparison between animals born early and late in the season. - Acta Agriculturae Scandinavica A 48: $122-128$.

Brisbin, I. L. \& Lenarz, M. S. 1984: Morphological comparisons of insular and mainland populations of southeastern white-tailed deer. - Journal of Mammalogy 65: 44-50.

Caro, T. 2005: The adaptive significance of coloration in mammals. - BioScience 55: 125-136.

Celi, R., Di Trana, A., Celi, P., Marsico, G. \& Forcelli, M. 2005: The influence of pregnancy and the beginning of lactation on pelage traits in cashmere goats. - Italian Journal of Animal Science 4: 85-95.

Davis, A. K. 2010: A technique for rapidly quantifying mammal hair morphology for zoological research. Folia Zoologica 59: 87-92.

Ferguson, J. H. 1985: Mammalian physiology. - Charles E. Merrill Publishing Company, Columbus, $\mathrm{OH}$.

Fox, M. W. 1969: The anatomy of aggression and its ritualization in Canidae: a developmental and comparative study. - Behaviour 35: 242-258.

Giltay, E. J. \& Gooren, L. J. G. 2000: Effects of sex steroid deprivation/administration on hair growth and skin sebum production in transsexual males and females. - Journal of Clinical Endocrinology \& Metabolism 85: 2913-2921.

Hilton, H. \& Kutscha, N. P. 1978: Distinguishing characteristics of hairs of eastern coyote, domestic dog, red fox and bobcat in Maine. - American Midland Naturalist 100: 223-227.

Inagaki, H. 1986: Morphological characteristics of the hair of japanese monkeys (Macaca fuscata fuscata): length, diameter and shape in cross-section, and arrangement of the medulla. - Primates 27: 115-123.

Jacobsen, N. K. 1980: Differences of thermal properties of white-tailed deer pelage between seasons and body regions. - Journal of Thermal Biology 5: 151-158.

Kennedy, A. J. 1982: Distinguishing characteristics of the hairs of wild and domestic canids from Alberta. Canadian Journal of Zoology 60: 536-541.

Korhonen, H. \& Harri, M. 1989: Wintering strategy of the raccoon dog as judged from its thermoregulatory properties. - Aquilo Ser. Zool. 24: 29-36.

Koul, G. L., Biswas, J. C. \& Somvanshi, R. 1987: Follicle and fiber characteristics of indian pashmina goats. Research in Veterinary Science 43: 398-400.

Kulak, D. \& Wajdzik, M. 2006: Morphological characteristics of hairs in the roe deer (Capreolous capreolus Linneus, 1758) from the Polish part of the Carpathian mountains. - Electronic Journal of Polish Agricultural Universities 9: 1-10.

Lucky, A. W., McGuire, J., Nydorf, E., Halpert, G. \& Nuck, B. A. 1986: Hair follicle response of the golden syrian hamster flank organ to continuous testosterone stimulation using silastic capsules. - Journal of Investigative Dermatology 86: 83-86.

Martinez, Z., Iniguez, L. C. \& Rodriguez, T. 1997: Influence of effects on quality traits and relationships between traits of the llama fleece. - Small Ruminant Research 24: 203-212.

McClure, P. A. \& Porter, W. P. 1983: Development of insulation in neonatal cotton rats (Sigmodon hispidus). Physiological Zoology 56: 18-32.

Moen, A. N. \& Severinghaus, C. W. 1984: Hair depths of the winter coat of white-tailed deer. - Journal of Mammalogy 65: 497-499.

Ogle, T. F. \& Farris, A. L. 1973: Aspects of cold adaptation in the coyote. - Northwest Science 47: 70-74.

Riggott, J. M. \& Wyatt, E. H. 1983: Mensuration of scanning micrographs. A possible means of hair identification. Science and Justice 23: 155-160.

Rowell, J. E., Lupton, C. J., Robertson, M. A., Pfeiffer, F. A., Nagy, J. A. \& White, R. G. 2001: Fiber characteristics of qiviut and guard hair from wild muskoxen (Ovibos moschatus). - Journal of Animal Science 79: 1670-1674.

Sağsöz, N., Kamac1, M. \& Orbak, Z. 2004: Body hair scores and total hair diameters in healthy women in the Kırıkkale region of Turkey. - Yonsei Medical Journal 45: 483-491.

Statistica 2003: Statistica ver. 6.1. - Statsoft Inc.

Tumlison, R. 1983: An annotated key to the dorsal guard hairs of Arkansas game mammals and furbearers. Southwestern Naturalist 28: 315-323.

Wynkoop, E. M. 1929: A study of the age correlations of the cuticular scales, medullas, and shaft diameters of human head hair. - American Journal of Physical Anthropology 13: 177-188. 